\title{
Observing snowmelt dynamics on fast ice in Kongsfjorden, Svalbard, with NOAA/AVHRR data and field measurements
}

\author{
Sascha Willmes, ${ }^{1}$ Jörg Bareiss, ${ }^{1}$ Christian Haas $^{2}$ \& Marcel Nicolaus ${ }^{3}$ \\ 1 Department of Environmental Meteorology, Behringstrasse 21, Campus II, University of Trier, DE-54286 Trier, Germany \\ 2 Department of Earth \& Atmospheric Sciences, 1-26 Earth Sciences Building, University of Alberta, Edmonton, Alberta T6G 2EG, Canada \\ 3 Norwegian Polar Institute, Polar Environmental Centre, NO-9296 Tromsø, Norway
}

\begin{abstract}
Keywords
Climate variability; remote sensing; sea ice; snowmelt detection; Svalbard.

Correspondence

Sascha Willmes, Department of Environmental Meteorology, Behringstrasse 21, Campus II, University of Trier, DE-54286 Trier, Germany. E-mail: willmes@uni-trier.de doi:10.1111/j.1751-8369.2009.00095.x
\end{abstract}

\begin{abstract}
Temporal snowmelt dynamics on fast ice in Kongsfjorden/Svalbard are studied for the period 1990-2003, using visible and near-infrared channels of the Advanced Very High Resolution Radiometer (AVHRR). Long-term radiation data from an adjacent Baseline Surface Radiation Network station, as well as extensive glaciological and meteorological field measurements on the melting ice in 2002 and 2003, are used to validate a snowmelt index derived from the satellite data. This study shows that the remote sensing data are in good agreement with the field observations. However, the temporal variability of atmospheric water vapour has an impact on the snowmelt index, and must be accounted for through atmospheric correction. The analysis of long-term satellite data provides valuable insight into the strength and rate of the snowvolume decay, and reveals a strong interannual variability of the snowmelt intensity. However, a precise date for determining melt onset requires clear-sky AVHRR data throughout the onset period.
\end{abstract}

The seasonal variability of sea ice, and its snow cover, is a key parameter for the investigation of the role of polar regions in climate change scenarios. Changes in sea-ice cover are capable of triggering and amplifying global climate changes (Curry et al. 1995). Sea ice is characterized by high temporal variability, and the overlying snow is very sensitive to atmospheric and radiative forcing. Knowledge of the seasonal snow-cover dynamics is essential to understand the formation and decay of sea ice. Snowmelt dynamics represent an important factor for the sea-ice mass balance, where meltwater percolating downwards triggers the formation of superimposed ice (Nicolaus et al. 2003; Kawamura et al. 1997). A very low thermal conductivity causes the snow cover to effectively suppress the energy exchange at the ocean-iceatmosphere boundary. Moreover, the extinction of photosynthetically active radiation makes snow a limiting factor for biological primary production under the ice (Gerland et al. 1999). The surface processes taking place during the transition from winter to summer are combined with a large albedo decrease, and consequently affect the regional surface heat budget (Holt $\&$ Digby 1995; Perovich et al. 2002). Hence, detecting the spa- tiotemporal variability of snowmelt patterns, and the onset and duration of melting, is crucial with regards to studies of global change.

Several approaches have been made so far in order to determine the onset of snowmelt through satellite information. Data from passive microwave radiometers can be used to identify the formation of meltwater within the snow pack, through a strong increase in surface brightness temperatures (Comiso 1983; Anderson 1997). Drobot \& Anderson (2001) and Belchansky et al. (2004) use this feature to derive Arctic-wide snowmelt onset maps for the period 1979-2001. Passive microwave satellite data are independent of surface illumination, but have a low spatial resolution compared with optical sensors, so that surface processes in narrow fjords can not be observed with these data. Radar sensors (SARs) yield a substantially higher resolution, and provide valuable data for snowmelt detection (Gogineni et al. 1992). However, their availability for longer time scales is limited.

Visible and near-infrared satellite imagery provides a convenient compromise of spatial and temporal resolution for the monitoring of snowmelt processes in fjords, as the spectral reflection of snow is significantly modified 
when intergrain meltwater develops (Perovich 1996; De Abreu et al. 2001; Zhang et al. 2003; Winther et al. 2004). De Abreu (1996) suggested the use of a twochannel index with Advanced Very High Resolution Radiometer (AVHRR) data to observe changes in sea-ice and snow surface conditions in the Canadian Arctic Archipelago. The Normalized Difference Snow and Ice Index (NDSII) utilizes the characteristic changes of the spectral albedo of snow after the formation of meltwater, and thus indicates the onset of the melt.

This paper intends to test the ability of the NDSII, as suggested by De Abreu (1996), to detect snowmelt on fast ice in the environment of narrow fjords. The area under investigation is Kongsfjorden in north-western Svalbard. The research settlement of Ny-Ålesund is located in this fjord, and several adjacent scientific stations have provided ground-based meteorological data continuously since 1993. Consequently, this area offers a great opportunity to validate remotely sensed surface information through the permanent presence of high-quality meteorological instrumentation. We assess the NDSII by comparing high-resolution in situ measurements of the physical snow properties on fast ice in Kongsfjorden with the coincident index evolution from May to June. The field data were acquired in Kongsfjorden during the Surface Energy Budget and Its Impact on Superimposed Ice Formation (SEBISUP) field campaigns in 2002 and 2003 (Nicolaus et al. 2003). Additionally, a 10-year time series from an adjacent meteorological station in Ny-Ålesund (1993-2003) is used to discuss the index evolution in the melting seasons prior to the years with available ground data.

\section{Data and methods}

Visible and near-infrared satellite imagery is used to obtain the dynamics of snowmelt on fast ice in Kongsfjorden for the period 1990-2003, by means of a normalized difference melt index. To validate the satellite-derived snowmelt patterns, radiation data from a Baseline Surface Radiation Network (BSRN) were used along with in situ and meteorological data from the SEBISUP field experiments.

\section{Study area}

The study area of Kongsfjorden is about $25 \mathrm{~km}$ long and $5-10 \mathrm{~km}$ wide. The glacier Kongsbreen is situated at the head of the fjord. The BSRN station is located in $\mathrm{Ny}$-Ålesund on the Brøggerhalvøya peninsula at $78.93^{\circ} \mathrm{N}$, $11.95^{\circ} \mathrm{E}$, on the southern edge of the fjord, at $11 \mathrm{~m}$ a.s.l. The physical environment of Kongsfjorden was described by Svendsen et al. (2002). Field measurements during the SEBISUP campaign were performed on 0.8-m-thick fast ice at Konsfjorden, close to the island of Gerdøya $\left(78.96^{\circ} \mathrm{N}, 12.26^{\circ} \mathrm{E}\right)$, from the middle of May to the beginning of June (Fig. 1). This location was selected because the first year fast-ice cover lasts until July, and the snow conditions are representative for eastern Kongsfjorden.

\section{Satellite data}

Daily AVHRR Polar $1 \mathrm{~km}$ Level $\mathrm{lb}$ imagery was used to observe snowmelt. Local Area Coverage (LAC) data were obtained from the National Oceanic and Atmospheric
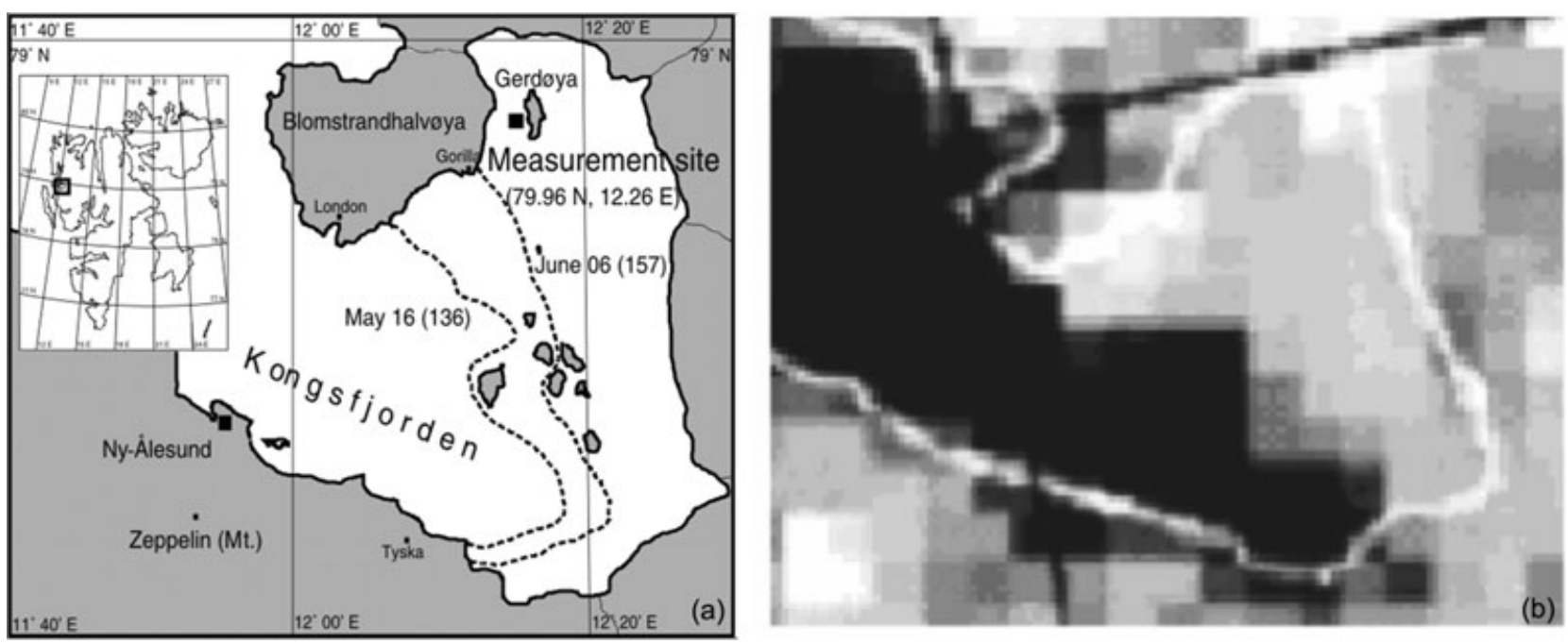

Fig. 1 (a) Map of Kongsfjorden showing the location of the measurement site and the fast-ice edges (dotted lines) on 16 May and 6 June 2002 (Nicolaus et al. 2003). (b) Advanced Very High Resolution Radiometer (AVHRR) channel 2 subset image of the same area on 16 May 2002. 
Administration (NOAA) Comprehensive Large Arraydata Stewardship System (CLASS) for the period of 19902003. Preprocessing of satellite data included geometric and radiometric corrections with TERASCAN software. The spatial resolution of the LAC data is $1.1 \mathrm{~km} \times 1.1 \mathrm{~km}$ at the centre line of a swathe, degrading to a few kilometres at the swathe edges. On average, 72 satellite images were available in each year for the months of May and June. Manual cloud-detection techniques were used to select images without clouds obscuring the Kongsfjorden area. To account for a potential influence of the bidirectional reflectance, we skipped images where the area of interest was located at the edge of swathes.

\section{Normalized Difference Snow and Ice Index (NDSII)}

The normalized difference methods allow long-term studies of broad-scale regions to be made, when complicated modelling of the atmospheric influence is not practicable. In this study, we utilize the NDSII to monitor surface melt processes on sea ice, as suggested by De Abreu (1996). The index is computed as follows:

$$
\mathrm{NDSII}=\left(\mathrm{AVHRR}_{1}-\mathrm{AVHRR}_{2}\right) /\left(\mathrm{AVHRR}_{1}+\mathrm{AVHRR}_{2}\right)
$$

Dry snow is characterized by a very high spectral albedo, between 400 and $1200 \mathrm{~nm}$, with only a slight decrease towards near-infrared wavelengths. This feature causes very low NDSII values. A reduction in the bulk albedo as well as a higher difference between the AVHRR channel 1 (580-680 nm) and the AVHRR channel 2 (720-1 $100 \mathrm{~nm})$ albedos cause an increase of the index. This makes the NDSII sensitive to the magnitude and shape of the albedo spectra. Consequently, as the first appearance of liquid water in a snow volume causes a strong albedo drop in near-infrared wavelengths only, the index should respond with a sudden increase, which in turn can be identified as the onset of the melt.

Moreover, the index is sensitive to the type of input data. The top of the atmosphere (TOA) reflectances or, alternatively, the bottom of the atmosphere (BOA) reflectances can be used. Differences between TOA- and BOA-derived NDSII values are mainly the result of atmospheric water vapour (AWV), which affects the atmospheric transmission of wavelenghts in AVHRR channel 2. In this study, we estimate the sensitivity of the TOA-based index to AWV by modelling TOA values of the NDSII from estimated BOA index values. This is accomplished by applying different atmospheric conditions to the radiative transfer model used in ATCPRO software (Hill \& Mehl 2003), which includes wavelength-dependent absorption properties of various atmospheric gases, including AWV.

\section{Station data}

Surface radiation data, including the surface radiation budget $\left(R^{*}\right)$, were obtained from the BSRN station in Ny-Ålesund, an international cooperative network set up by the World Climate Research Programme (WCRP). The BSRN station is operated by the Alfred Wegener Institute for Polar and Marine Research (AWI), and has been in operation since August 1992. Kipp \& Zonen CM 11 pyranometers are installed to measure the incoming and reflected short-wave radiation at this site. Eppley pyrgeometers are used to obtain incoming and outgoing longwave radiation. Radiation data with 5-min intervals are provided from March 1992 to July 1998, and with 1-min intervals from August 1998 to June 2003. The temporal variability of the surface energy balance ( $Q^{*}$; Eq. 2 ) is a good measure for melt-related surface processes, as changes in radiation and energy fluxes can trigger snow metamorphism, and the formation of meltwater.

The surface radiation balance is included in the BSRN data set, but in order to obtain the evolution of the surface energy balance between May and June from 1993 to 2003 , turbulent fluxes of latent $\left(Q_{\mathrm{E}}\right)$ and sensible $\left(Q_{\mathrm{H}}\right)$ heat had to be calculated. This was achieved using an aerodynamic approach (Launiainen \& Cheng 1995). The input data for this method are as follows: surface temperatures, which were derived from the long-wave outgoing radiation; wind speed at $10 \mathrm{~m}$ above the level of the snow; air temperature and relative humidity at $2 \mathrm{~m}$ above the level of the snow; as well as the air pressure at sea level. These data are provided by the Norwegian Polar Institute in their collection of meteorological tower measurements held in Ny-Ålesund. The conductive heat flux $\left(Q_{\mathrm{C}}\right)$ is assumed to be zero in this study, as the snow and ice volume is close to melting, which means we have nearly isothermal conditions.

$$
Q^{*}=R^{*}+Q_{\mathrm{H}}+Q_{\mathrm{E}}+Q_{\mathrm{C}}\left(\mathrm{W} \mathrm{m}^{-2}\right)
$$

The values of $Q^{*}$ were calculated as daily mean values from observations taken every $3 \mathrm{~h}$. For the correction of the satelite data, values of AWV were acquired from daily upper-air soundings, performed by AWI at Koldewey station in Ny-Ålesund.

\section{SEBISUP data}

During the SEBISUP field campaigns in 2002 and 2003, meteorological and glaciological field measurements were performed on the melting fast ice. A meteorological station was equipped with two Kipp \& Zonen CM 22 pyranometers and two Eppley pyrgeometers to measure all components of the long-wave and short-wave radiation balance. Air temperature, relative humidity, as well 
as wind velocity and wind direction $2 \mathrm{~m}$ above the snow surface, were measured using an automatic weather station (AWS). Snow and ice measurements were collected at a distance of about $10 \mathrm{~m}$ from the AWS. The snow thickness was measured with a horizontal spacing of $1 \mathrm{~m}$ along a 50-m representative profile, with the aid of a ruler stick, once a day at noon. Vertical profiles of snow temperature and wetness were measured daily along the profile in hourly intervals. The snow temperature was acquired with a hand-held Pt-100 thermometer, and snow wetness was measured using a dielectric resonator probe (snow fork; Shivola \& Tiuri 1986) to calculate the percentage of liquid water content. The density of the snow cover was obtained by weighing a defined volume $(0.5$ l) of snow. The spectral albedo was recorded with a Spectron Engineering SE 590 spectroradiometer at 256 wavelengths between 396 and $1075 \mathrm{~nm}$. Additionally, ice cores were drilled on nine days at different positions of the snow-thickness profile to measure sea-ice thickness, as well as vertical profiles of temperature and salinity. The crystal texture was observed by means of thick sections viewed between crossed polarizers (Nicolaus et al. 2003).

\section{Results}

\section{Influence of atmospheric water vapour}

The AVHRR measurements in channels 1 and 2 are both affected by the absorption bands of atmospheric gases. Ozone, which is assumed to be constant in time for this study, absorbs some of the radiation that is collected by the visible channel. AWV, which is highly variable, lowers the atmospheric transmission in the near infrared. Therefore, it is necessary to estimate the sensitivity of the NDSII to the temporal variability of AWV. To achieve this, the in situ measured BOA albedos of three different surface types (new snow, melting snow and old snow; see Table 1) were used to calculate TOA albedos for different atmospheric conditions (using AWV values from radio soundings). NDSII values were subsequently calculated from the simulated TOA albedo to investigate how they change with increasing AWV. The results are presented in Fig. 2. For AWV values that are close to zero, the TOA

Table 1 Surface albedo in the spectral range of the Advanced Very High Resolution Radiometer (AVHRR) channels 1 and 2, and coincident Normalized Difference Snow and Ice Index (NDSII) values for three surface types. Data are taken from SEBISUP 2002 spectral albedo measurements.

\begin{tabular}{llll}
\hline & AVHRR channel 1 & AVHRR channel 2 & NDSII \\
\hline New snow & 0.96 & 0.91 & 0.027 \\
Snow (melt onset) & 0.93 & 0.82 & 0.063 \\
Old snow & 0.46 & 0.39 & 0.082 \\
\hline
\end{tabular}

NDSII is lower than the BOA NDSII, as a result of ozone absorption in channel 1 , and consequently leads to an underestimation of NDSII. The opposite case happens with increasing AWV. This implies that a rapid increase of AWV in the monitoring period could produce TOA NDSII increases that are not related to changes in surface conditions.

A polynomial model was fitted to the relationship between AWV and the NDSII offset between TOA and BOA albedo values (Fig. 3). Subsequently, the NDSII from satellite-measured TOA reflectance data was added as an offset, depending on the level of AWV for the respective day. From this, we obtained the time series of AWV-corrected TOA NDSII values for each year from 1990 to 2003, between day of year (DOY) 120 (30 April) and 180 (29 June). Figure 4 presents a comparison of the corrected and uncorrected NDSII values in a time series of data for the years 2002 and 2003. After correction, the NDSII is generally lower than before. The strong index increase occurring at DOY 142 in 2002 was apparently caused by a coincident increase in AWV. After the calculated offset was added, the date of the NDSII increase was shifted to DOY 147.

\section{NDSII and field measurements}

The NDSII, calculated as a spatial average for the fast-ice area in Kongsfjorden between DOY 120 (30 April) and

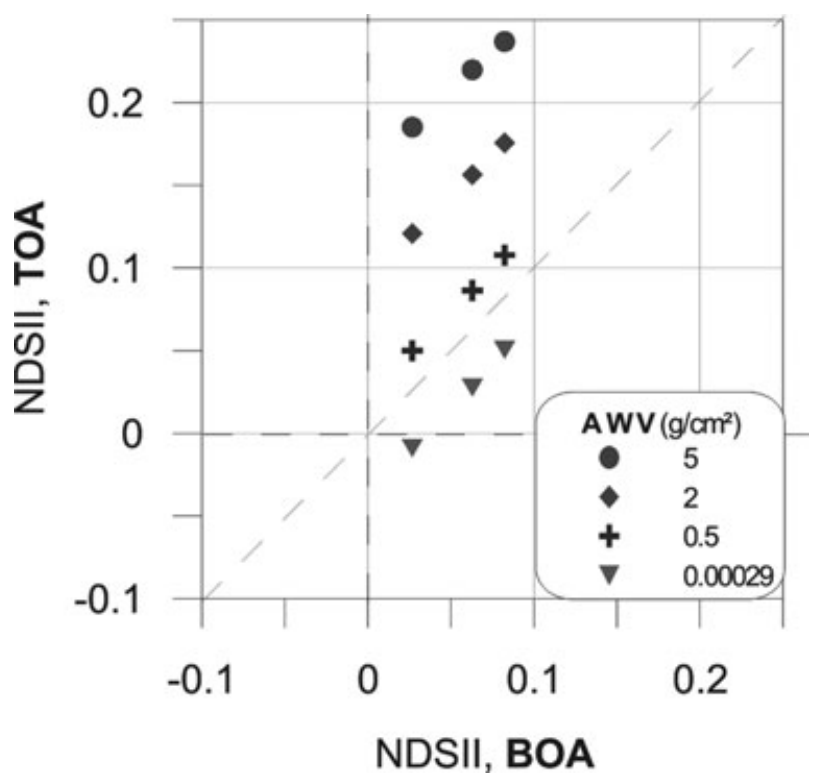

Fig. 2 The Normalized Difference Snow and Ice Index (NDSII) from the modelled top of the atmosphere (TOA) reflectances, plotted against three different bottom of the atmosphere (BOA) NDSIIs, with changing levels of atmospheric water vapour (AWV). The TOA reflectances are calculated with ATCPRO. 
180 (29 June), is presented in Fig. 4 for the years of 2002 and 2003. Both time series show positive trends during the ablation period. The fact that fewer clear-sky images were available for 2003 leads to less available NDSII values. The subsequent discussion is based on the corrected time series shown in Fig. 4b. The 2002 NDSII values oscillated at values below 0.1 , before increasing sharply to values of 0.14 at DOY 147 (27 May), and to even higher values after that. The time series for 2003 appears to be quite different: the NDSII does not exceed 0.05 before DOY 162 (11 June). A very weak increase can be found between DOY 146 (26 May) and DOY 161 (10 June), but the most pronounced rise occurs directly afterwards.

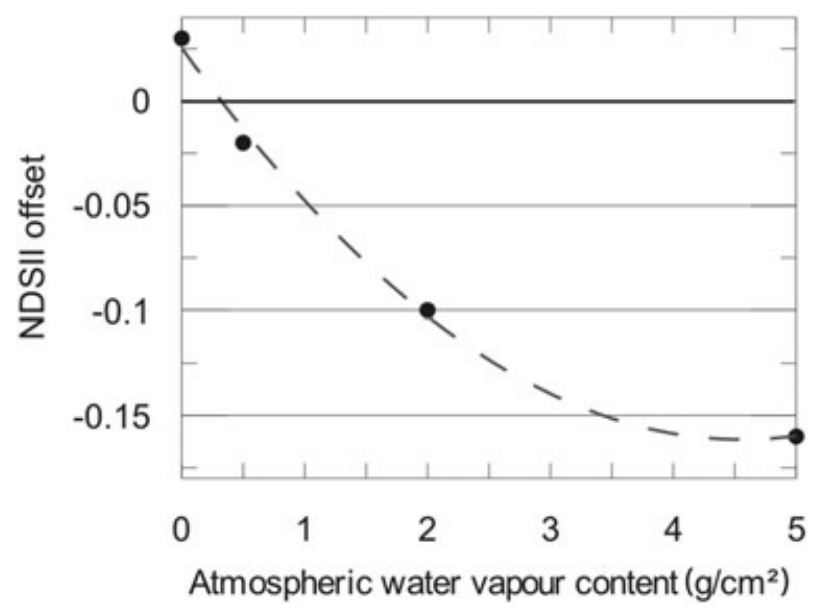

Fig. 3 The Normalized Difference Snow and Ice Index (NDSII) offset with changing levels of atmospheric water vapour (AWV), as taken from ATCPRO results $(\mathbf{)}$ ) and the fitted polynomial model (dashed line).
The SEBISUP field campaigns provide measurements of vertical snow temperature, wetness and density profiles from 20 May to 4 June 2002, and from 15 May to 5 June 2003. The first SEBISUP year (2002) was characterized by a sharp transition from dry to melting snow cover in the sampling period, whereas in 2003 the snow-cover decay was less differentiated (Nicolaus 2006). Figure 5 summarizes the evolution of snow height and broad-band albedo at the field station for the two years studied. In 2002, the snow cover on fast ice in the middle of May was about $22 \mathrm{~cm}$ thick. This snow volume was very stable until the end of May (DOY 148), when thickness decreased sharply to pratically zero within just 4 days. Snow melt was initiated by a drastic $70 \mathrm{~W} \mathrm{~m}^{-2}$ increase of the incoming long-wave radiation at DOY 147 (Nicolaus et al. 2003). Approximately 2 days after the commencement of snow thinning the broad-band albedo, as calculated from the SEBISUP radiation measurements, shows a strong drop from 0.7 to less than 0.4. In 2003, however, the snowcover thickness in the middle of May was $10 \mathrm{~cm}$ less than that in 2002, and decreased continuously and slowly, so that $5 \mathrm{~cm}$ of snow was still left at the beginning of June. At that time the surface albedo was more than 0.7, still very high compared with 2002 values.

During the SEBISUP 2002 experiment, a sudden change in the properties of the snow cover was observed at the end of May, with the result that the snow was partly melted and partly transformed to superimposed ice at the begining of June. In 2003, the melt conditions were characterized by a snow cover that already started to decay in the middle of May, but then continued degrading very slowly without any abrupt transitions. Early in 2003, snow internal temperatures were close to zero, whereas one year before, the melting point was not (a)

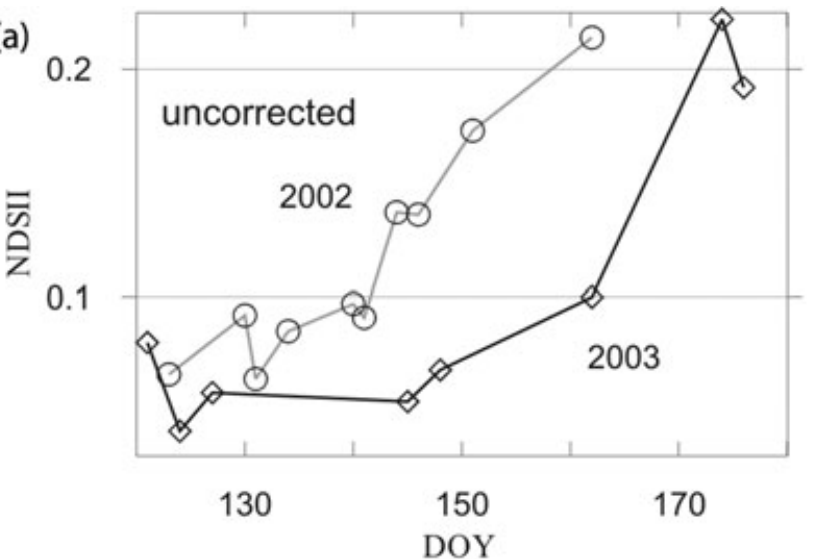

(b)

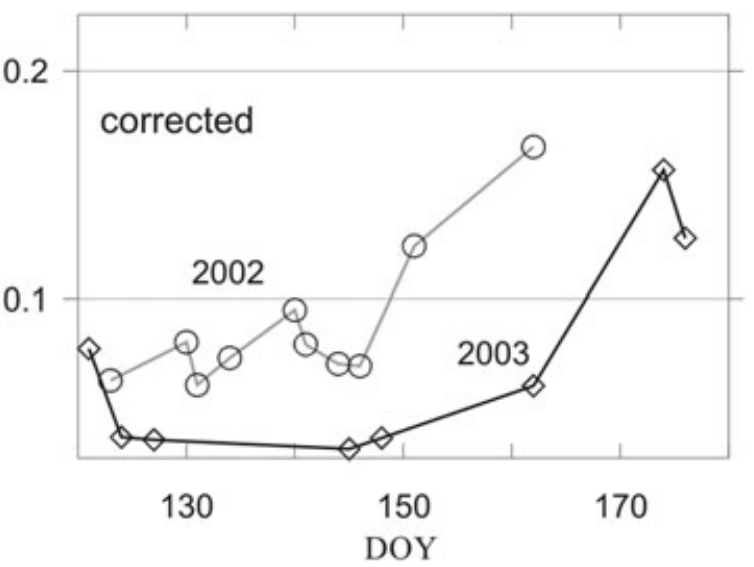

Fig. 4 Time series of the Normalized Difference Snow and Ice Index (NDSII) for 2002 and 2003, between day of year (DOY) 120 (30 April) and 180 (29 June), on fast ice in Kongsfjorden. (a) Top of the atmosphere (TOA) values of NDSII. (b) TOA values corrected for atmospheric water vapour (AWV). Coincident ground measurements were performed in these years. 

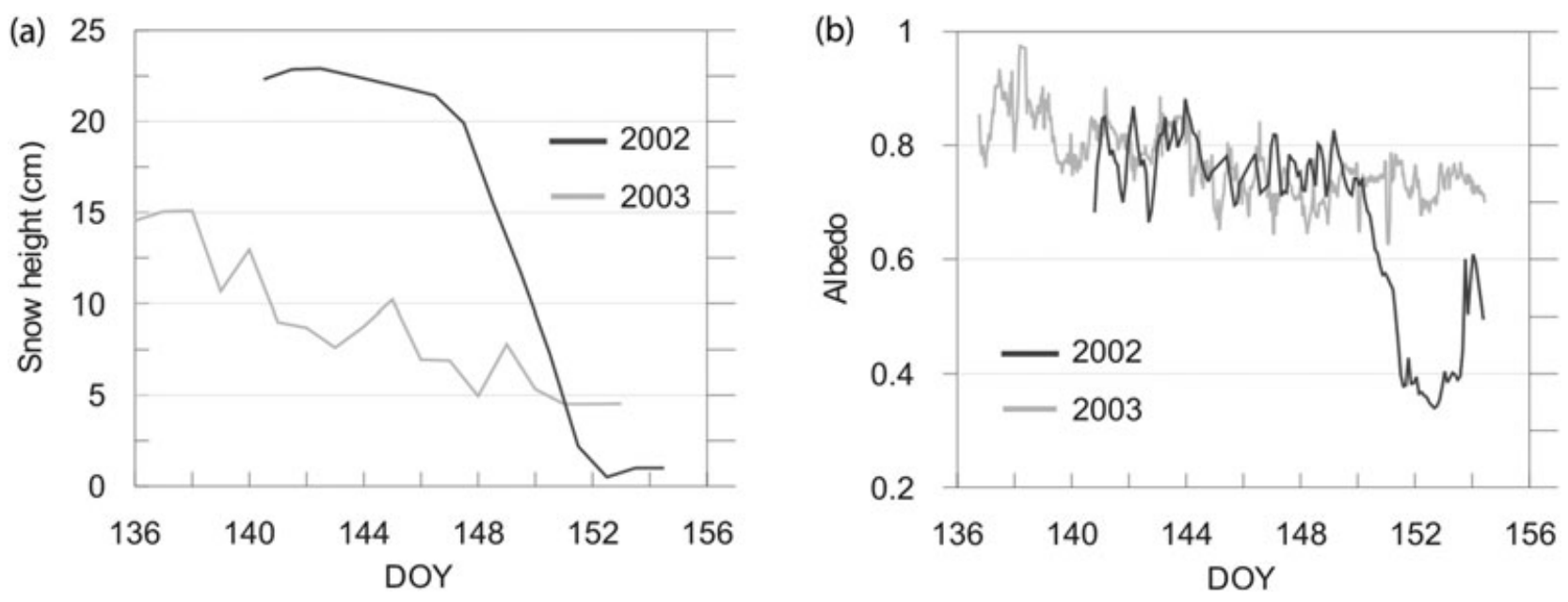

Fig. 5 Time series of (a) the snow height and (b) the integral surface albedo (automatic weather station data), for the period between day of year (DOY) 136 (16 May) and 156 (5 June), measured at the SEBISUP field station, Kongsfjorden, in 2002 and 2003.

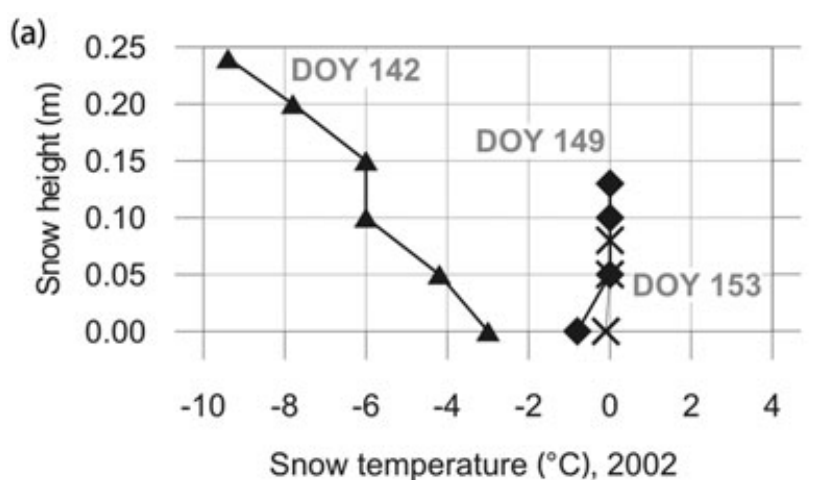

(c)

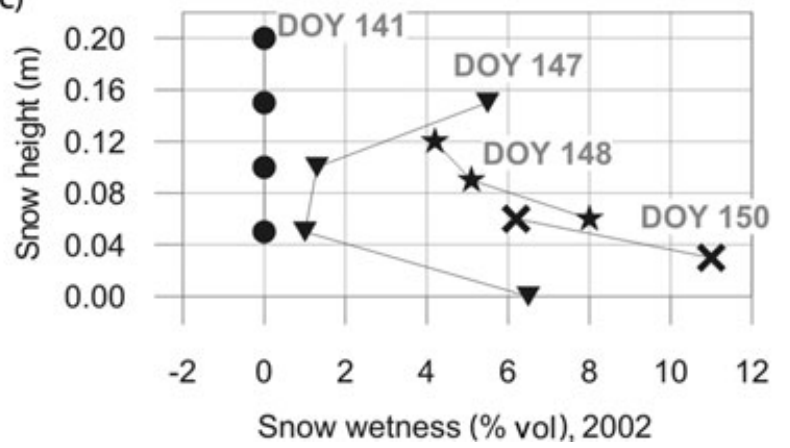

(b)

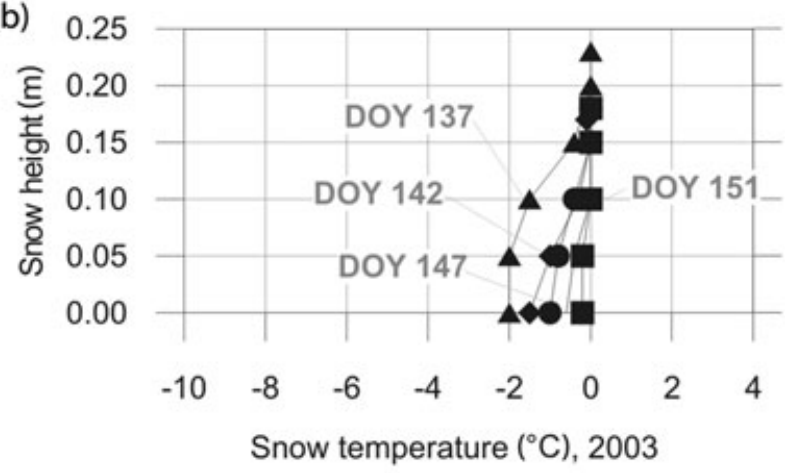

(d)

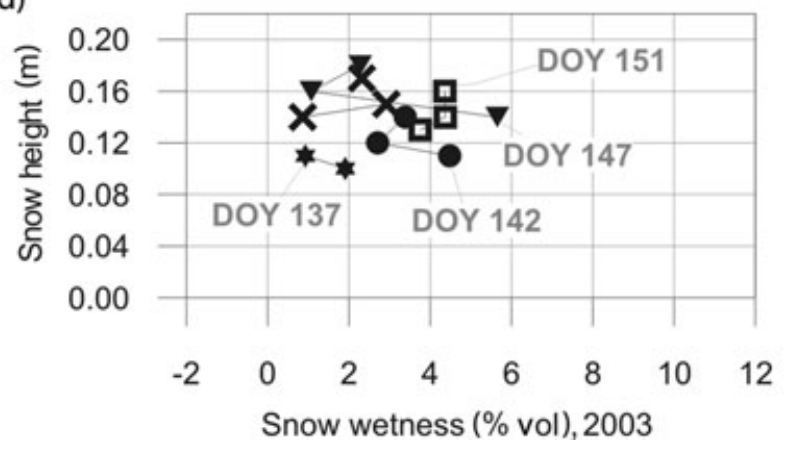

Fig. 6 Time series of the mean vertical profiles of $(a, b)$ snow temperature and $(c, d)$ snow wetness, measured at the SEBISUP field station, Kongsfjorden, in 2002 and 2003.

reached before the end of May. Snow wetness was very high from the start of data collection in 2003, and could not be sampled from below a snow height of $0.1 \mathrm{~m}$, as hard superimposed ice layers had already formed below (Fig. 6).

Figure 7 gives an example of how the in situ measured spectral albedo of snow at the SEBISUP field station changed with approaching summer conditions between DOY 141 (21 May) and 152 (1 June) in 2002. The corresponding NDSII value is shown in brackets. The reflectance drop in the near-infrared wavelength region causes an NDSII increase from 0.016 to 0.078 at DOY 147 (27 May). The strong rise of corrected satellite-derived NDSII values (Fig. 4b) for 2002 also occurs at DOY 147. 
The NDSII values from satellite data turn out to be higher than those from the ground measurements, which results from differences in atmospheric transmission between

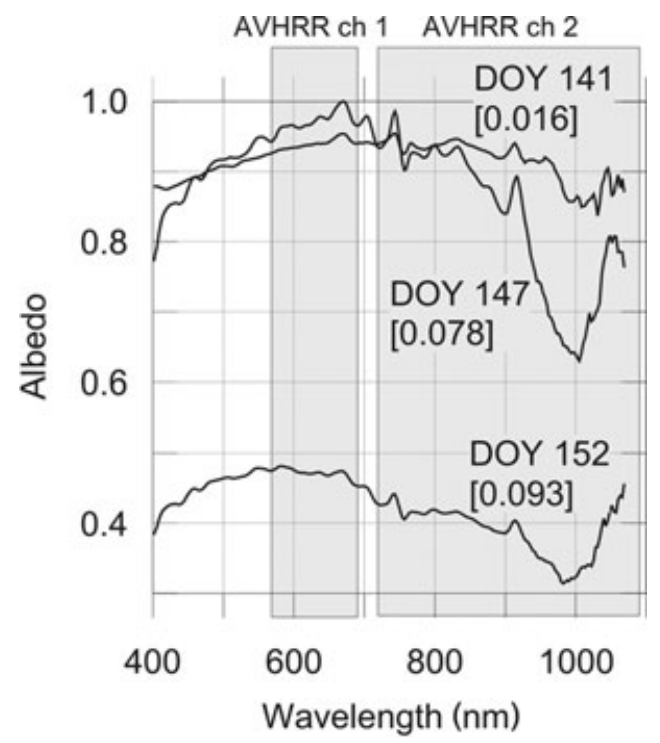

Fig. 7 Spectral albedos of snow cover on three different days during the SEBISUP field campaign in 2002. The numbers in square brackets denote the coincident Normalized Difference Snow and Ice Index (NDSII) values.
AVHRR channel 1 and 2. Unfortunately, spectral albedos could not be measured in 2003 because of an instrument malfunction.

\section{NDSII time series from 1990 to 2003}

The NDSII between DOY 120 (30 April) and 180 (29 June) over fast ice in Kongsfjorden shows a strong interannual variability in the period from 1990 to 2003 (Fig. 8). Each index value represents the spatial average of the fast-ice area in northern Kongsfjorden at a specific date (DOY). The fact that surface monitoring with AVHRR images is limited to clear-sky conditions results in very poor coverage of NDSII values for some years. The fewer clear-sky images that are available, the less structured the NDSII evolution appears. Data from 1994 are missing completely because too few useful satellite data could be obtained. NDSII values increased from May to June in all of the years studied. Table 2 summarizes the statistics of the calculated NDSII values. The mean spatial variance of the index values within the fast-ice area at a respective date is one order of magnitude lower than temporal variance from May to June. The year 1998 is outstanding, with NDSII values below zero in May, and generally lower values compared with the entire period of 19902003. A negative NDSII value can be caused by dust

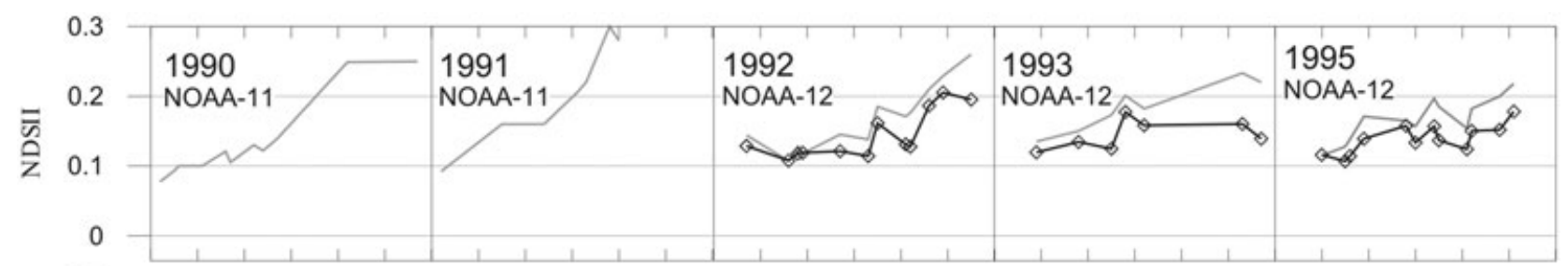

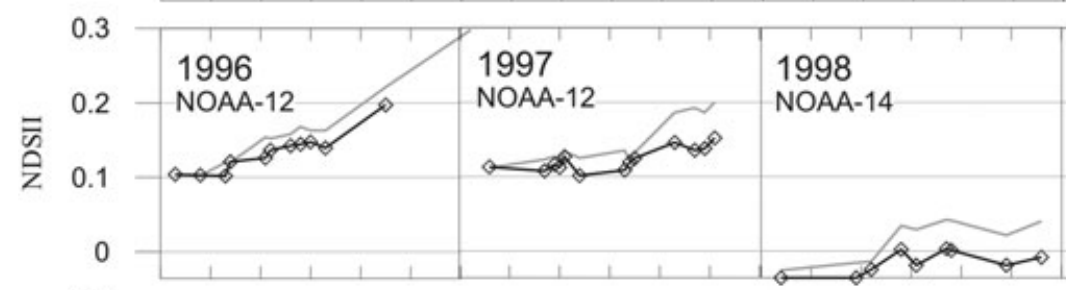
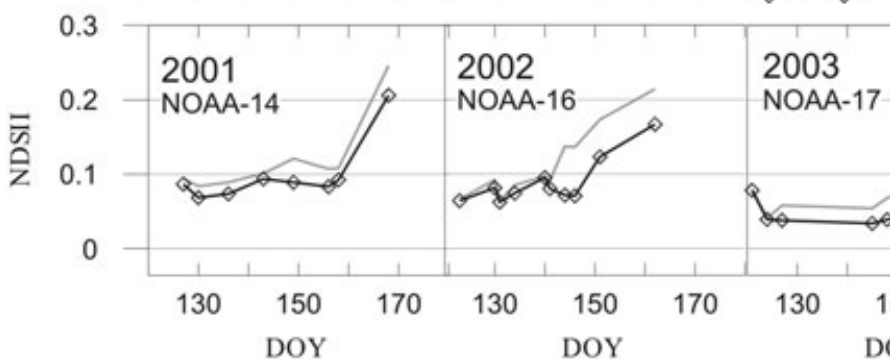
NOAA-16

Fig. 8 Time series of the spatially averaged Normalized Difference Snow and Ice Index (NDSII), measured between day of year (DOY) 120 (1 May) and 180 (29 June), from fast ice in Kongsfjorden, from 1990 to 2003 . The year 1994 is missing because of a lack of clear-sky satellite data. Note that the NDSII scale in 1998 differs from the other years because this was the only year with NDSII values below zero. 
particles on the surface of the snow from black carbon emissions, which tend to lower the reflection in visible wavelengths, and consequently accelerate the melt process. However, no data on snow impurities were available for Kongsfjorden. Besides the all-in-all increase from May to June, enhanced index jumps are present in some years. Sometimes, the abrupt NDSII increase is only a short positive deviation from the long-term increase (e.g., 1993 and 1995), whereas in most years, sudden increases are follwed by a continuously higher NDSII level (1990, 1991, 1992, 2000 and 2002).

\section{NDSII and surface energy balance}

To assess the suitability of an NDSII time series for the representation of surface conditions, different radiation

Table 2 Statistics of the calculated Normalized Difference Snow and Ice Index (NDSII) values.

\begin{tabular}{lc}
\hline NDSII statistics & Value \\
\hline Total $n$ & 296 \\
Mean & 0.139 \\
Minimum & -0.026 \\
Maximum & 0.47 \\
Total standard deviation & \pm 0.071 \\
Mean spatial standard deviation & \pm 0.008 \\
\hline
\end{tabular}

components from the BSRN station, and meteorological parameters from synoptic observations in Ny-Ålesund, were compared with the index evolution between May and June. The daily averaged surface energy balance (SEB), which is a trigger for the surface melt, is presented in Fig. 9. In all of the years studied, at the beginning of May the SEB oscillates around zero, and then increases until the end of June. The most pronounced increases occur around DOY 150, with the strength and velocity of the increase revealing a high interannual variability. In 2002, the time series of the daily mean SEB values between DOY 120 and 180 shows the strongest rise after DOY 142, and a maximum of approximately $200 \mathrm{~W} \mathrm{~m}^{-2}$ that was reached around DOY 161 (10 June). Previously, SEB values were generally close to zero, with the exception of values around $40 \mathrm{~W} \mathrm{~m}^{-2}$ from DOY 126 (6 May) to 134 (14 May). In 2003, the SEB oscillation around zero was of longer duration, and a less pronounced increase only occurred after DOY 150 (30 May).

This observation is supported by the NDSII evolution and ground measurements. In 2002, NDSII values increase almost continuously, with an intermediate jump at DOY 147, whereas in 2003, the NDSII seems to be nearly constant until DOY 148, when a slight increase lifts the index values slowly. Consequently, SEB and NDSII evolution, as well as in situ data from snow measurements, support each other in reflecting the start of drastic

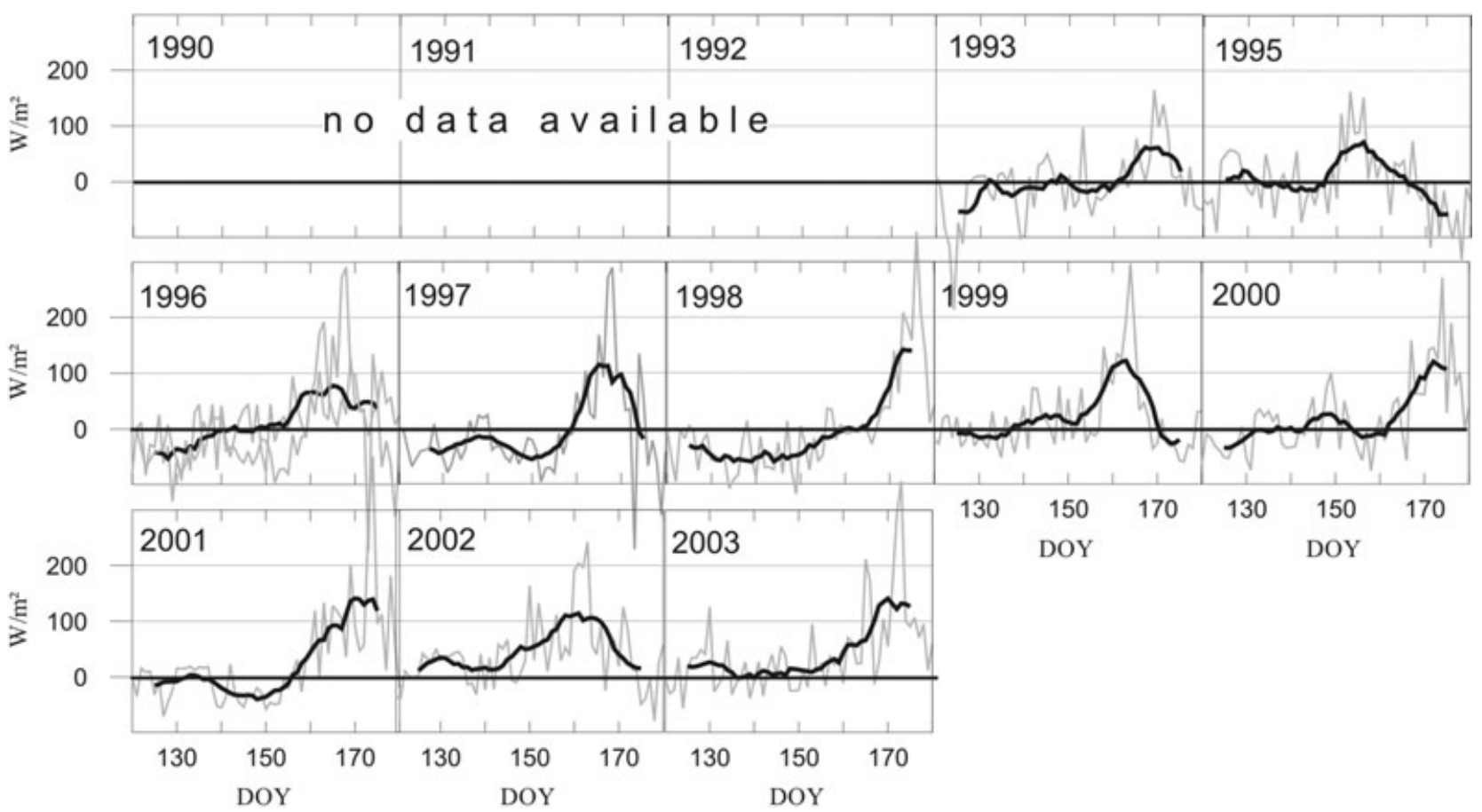

Fig. 9 Daily mean surface energy balance between day of year (DOY) 120 (29 April) and 180 (29 June) for the years from 1993 to 2003 , and the 10 -day running average (in bold), from Baseline Surface Radiation Network (BSRN) data and meteorological tower measurements, in Ny-Ålesund. 


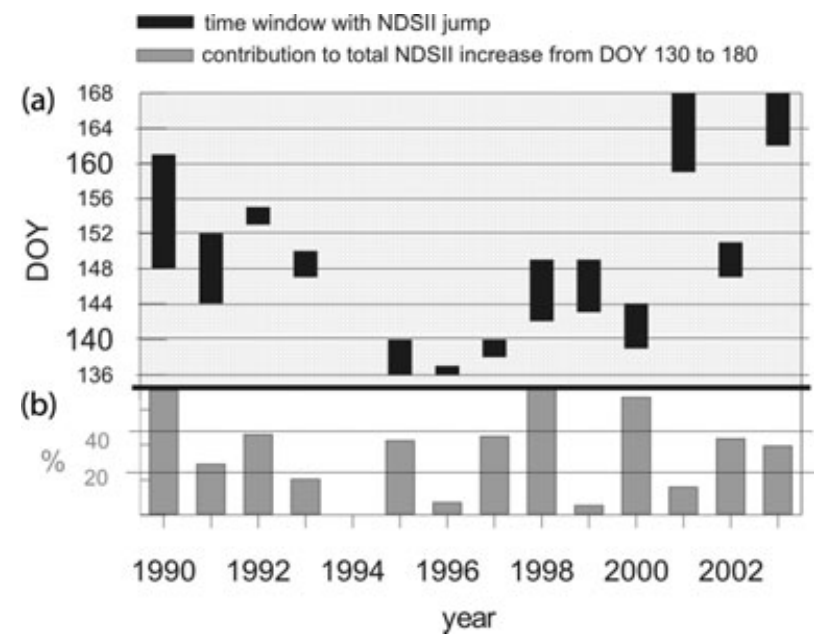

Fig. 10 Melt onset periods for fast ice in Kongsfjorden. The black bars in (a) mark the time windows for melt onset, as detected from Normalized Difference Snow and Ice Index (NDSII) jumps. The grey bars in (b) denote the contribution of the identified NDSII jump to the total NDSII increase between day of year (DOY) 130 and 180.

surface changes around DOY 147 in 2002, and the much less pronounced surface transition in 2003.

\section{Interannual variability of melt onset}

Figure 10 summarizes the results of a manual detection of melt-onset periods from the NDSII time series. Depending on the availability of clear-sky, near-nadir AVHRR images, the melt-onset period is more or less sharply resolved temporally. If more than one date could be considered as melt onset, we always chose the first one. The result shows that melt periods on fast ice in Kongsfjorden were undergoing a change towards earlier onset from the beginning to the mid-1990s, whereas the melt periods have tended to occur slightly later since 1997 (Fig. 10a). Apart from interannual changes in the onset of the melt period, Fig. 10 reveals that the significance of the melt signal differs very much from year to year (Fig. 10b), such that in 1996, 1999 and 2001 the detected melt signal represents less than $20 \%$ of the total NDSII increase in the observational period. Figure 10 also reflects the described differences in the ablation periods during the field measurements, with an early/strong melt in 2002 and a late/weak melt in 2003. The NDSII, in combination with the SEB time series, reveals years of early melt in 1995, 1996 and 1997, and years of late melt in 2001 and 2003, as well as years of weak melt in 1996 and 1999, and years of strong melt in 1990, 1998, 2000 and 2002.

\section{Discussion and conclusions}

This study aimed to evaluate the NDSII index for the long-term monitoring of snowmelt processes in narrow fjords. The NDSII index for the period between 1 May and 30 June was derived for 13 years, from 1990 to 2003, for the fast-ice area in Kongsfjorden/Svalbard. For the years of 2002 and 2003, field data were available to validate observed changes of the NDSII. The characteristic differences of the melt periods observed in situ in 2002 and 2003 were satisfactorily reflected in the NDSII. The interannual differences in the evolution of the SEB in Ny-Ålesund, at the transition from spring to summer, were also shown to be reflected in the NDSII. Snowmelt onset periods were manually identified from the derived NDSII time series. Our results show snowmelt varying strongly in strength and date of onset within the observational period. Detection of a melt onset date with daily accuracy would require daily coverage of clear-sky, nearnadir images.

Interannual variations in the absolute NDSII values may partly result from intersatellite calibration differences. Moreover, snow bidirectional reflectance variations will have a significant effect on the NDSII values. We tried to mitigate the latter effect by limiting our analysis to near-nadir images. Thus, the evolution of NDSII values between DOY 120 and 180 presented is likely to represent real changes in surface conditions. Variations in the shape of the NDSII time series from May to June can reveal differences in the rate and strength of snow-cover decay (De Abreu et al. 2001). The NDSII increase from May to June results from a decrease of the bulk albedo, and the increasing difference between visible and near-infrared albedos of the snow cover. Rapid increases of NDSII are likely to represent the latter process. Considering that ice break-up might occur as early as June, one must take into account that very high index values at the end of the monitoring period can be biased by subpixel-sized open-water fractions. As stated by De Abreu (1996), the formation of melt ponds results in strong NDSII increases.

The interpretation of NDSII for the years without coincident field data is difficult, and is limited by the availability of clear-sky data. However, they still offer insight into the strength and rate of snow-cover decay. The correction of satellite data with regards to AWV shows that in most cases the corrected NDSII time series turn out to be lower than the uncorrected time series, with more or less the same shape, but with an increasing difference towards the end of the monitoring period. The latter observation is explained by a generally increasing AWV content from May to June. The investigation of uncorrected index values may lead to a misinterpretation of abrupt index rises, as is shown for the year 2002, where the recorded date of the enhanced NDSII increase shifted to a few days later after the influence of water vapour was included. 
The analysis presented allows for a rough overview on the interannual variations of snowmelt strength and seaice surface decay for fast ice in Kongsfjorden. The manual detection of melt onset windows reveals years of early melt and years of late melt, as well as years of weak melt and years of strong melt. Follow-on investigations should try to develop a more detailed algorithm for picking melt onset dates from the combined time series of the NDSII, AVHRR albedos and surface temperatures.

\section{Acknowledgements}

JB was working at the Alfred Wegener Institute for Polar and Marine Research, Bremerhaven, Germany, when the work presented in this paper was carried out. The authors would like to thank the staff at the Sverdrup (Norwegian Polar Institute) and Koldewey (Alfred Wegener Institute) stations in Ny-Ålesund. The helpful comments of two anonymous reviewers are strongly acknowledged. Radiometers and meteorological instruments were kindly provided by Gert König-Langlo, Bernd Loose, Alfred Helbig and Uwe Baltes. The use of AVHRR LAC and GAC data, through the NOAA CLASS, formerly known as the Satellite Active Archive (SAA), is greatly acknowledged. The SEBISUP measurements were performed at the former Ny-Ålesund Large Scale Facility under ECLSF grant NP-9/2001 with the support of the Alfred Wegener Institute. This study was partly funded by the German Research Foundation (DFG) under contract BA 2060/2-2 and HA 2724/4-2 and by the MariClim project funded through NFR (Norwegian Research Council).

\section{References}

Anderson M. 1997. Determination of a melt-onset date for Arctic sea-ice regions using passive-microwave data. Annals of Glaciology 25, 382-388.

Belchansky G.I., Douglas D.C., Mordvintsev I.N. \& Platonov N.G. 2004. Estimating the time of melt onset and freeze onset over Arctic sea-ice area using active and passive microwave data. Remote Sensing of Environment 92, 21-39.

Comiso J.C. 1983. Sea ice effective microwave emissivities from satellite passive microwave and infrared observations. Journal of Geophysical Research-Oceans 88, 7686-7704.

Curry J.A., Schramn J.L. \& Ebert E.E. 1995. On the ice albedo climate feedback mechanism. Journal of Climate 8 , 240-247.

De Abreu R. 1996. In situ and satellite observations of the visible and infrared albedo of sea ice during spring melt. PhD thesis, University of Waterloo, ON, Canada.

De Abreu R., Yackel J., Barber D. \& Arkett, M. 2001. Operational satellite sensing of Arctic first-year sea ice melt. Canadian Journal of Remote Sensing 27, 487-501.
Drobot S.D. \& Anderson M. 2001. An improved method for determining snowmelt onset dates over Arctic seas using scanning multichannel microwave radiometer and Special Sensor Microwave/Imager data. Journal of Geophysical Research-Atmospheres 106, 24 033-24 049.

Gerland S., Winther J.-G., Ørbæk J.B., Liston G.E., Øritsland N.A., Blanco A. \& Ivanov, B. 1999. Physical and optical properties of snow covering Arctic tundra on Svalbard. Hydrological Processes 13, 2331-2343.

Gogineni S.P., Moore R.K., Grenfell T.C., Barber D.G., Digby S. \& Drinkwater M. 1992. The effects of freeze-up and melt processes on microwave signatures. In F.D. Carsey (ed.), Microwave remote sensing of sea ice. Pp. 329-341. Washington D.C.: American Geophysical Union.

Hill J. \& Mehl J. 2003. Geo- und radiometrische Aufbereitung multi- und hyperspektraler Daten zur Ergänzung langjähriger kalibrierter Zeitreihen. (Geometric and radiometric processing of multispectral and hyperspectral data to supplement calibrated long time series.) Photogrammetrie Fernerkundung Geoinformation 1, 7-14.

Holt B. \& Digby S.A. 1995. Processes and imagery of first-year fast sea ice during the melt season. Journal of Geophysical Research-Oceans 90, 5045-5062.

Kawamura T., Ohshima K.I., Takitzawa T. \& Ushio S. 1997. Physical, structural and isotopic characteristics and growth processes of fast sea ice in Lützow-Holm Bay, Antarctica. Journal of Geophysical Research-Oceans 102, 3345-3355.

Launiainen J. \& Cheng B. 1995. A simple non-iterative algorithm for calculating turbulent bulk fluxes in diabatic conditions over water, snow/ice and ground surface. Report Series in Geophysics 33. Helsinki: University of Helsinki.

Nicolaus M. 2006. Beobachtung und Modellierung der Schneeschmelze und Aufeisbildung auf arktischem und antarktischem Meereis. (Monitoring and modelling of snowmelt and superimposed ice formation on Arctic and Antarctic sea ice.) $\mathrm{PhD}$ thesis, Dept. of Geosciences, University of Bremen.

Nicolaus M., Haas C. \& Bareiss J. 2003. Observations of superimposed ice formation at melt-onset on fast ice on Kongsfjorden, Svalbard. Physics and Chemistry of the Earth 28, 1241-1248.

Perovich D.K. 1996. The optical properties of sea ice. CCREL Monograph 96(1). Hanover, NH: Cold Regions Research Engineering Laboratory.

Perovich D.K., Tucker W.B. \& Ligett K.A. 2002. Aerial observations of the evolution of ice surface conditions during summer. Journal of Geophysical Research-Oceans 107, 8084, doi: 10.1029/2000JC000449.

Shivola A. \& Tiuri M. 1986. Snow fork for field determination of the density and wetness profiles of a snow pack. IEEE Transactions on Geoscience and Remote Sensing 24, 717-721.

Svendsen H., Beszczynska-Møller A., Hagen J.O., Lefauconnier B., Tverberg V., Gerland S., Ørbæk J.B., Bischof K., Papucci C., Zajaczkowski M., Azzolini R., Bruland O., Wiencke C., Winther J.-G. \& Dallmann W. 2002. The physical environment of 
Kongsfjorden-Krossfjorden, an Arctic fjord system in Svalbard. Polar Research 21, 133-166.

Winther J.-G., Edvardsen K., Gerland S. \& Hamre B. 2004. Surface reflectance of sea ice and under-ice irradiance in Kongsfjorden, Svalbard. Polar Research 23, 115118.
Zhang T., Scambos T., Haran T., Hinzman L.D., Barry R.G. \& Kane D.L. 2003. Ground-based and satellite-derived measurements of surface albedo on the North Slope of Alaska. Journal of Hydrometeorology 4, 77-91. 